\title{
Is consumer confidence an indicator of JSE performance?
}

\author{
Kamini Solanki ${ }^{1}$, Yudhvir Seetharam ${ }^{1}$
}

\begin{abstract}
While most studies examine the impact of business confidence on market performance, we instead focus on the consumer because consumer spending habits are a natural extension of trading activity on the equity market. This particular study examines investor sentiment as measured by the Consumer Confidence Index in South Africa and its effect on the Johannesburg Stock Exchange (JSE). We employ Granger causality tests to investigate the relationship across time between the Consumer Confidence Index and market performance. The results show weak evidence of a contemporaneous relationship; however, significant evidence of a Granger caused relationship is apparent. Further, changes in investor sentiment Granger-cause changes in the two indices used, generally with a lag of 9 and 12 months, but not vice versa. Thus, we find that Consumer Confidence leads JSE performance during our sample period. Our research provides evidence contradicting the common perception of consumer confidence lagging market performance, particularly in the South African context.
\end{abstract}

KEY WORDS: $\quad$ consumer confidence; financial markets; South Africa; behavioral finance

JEL Classification: C01; C58; D53; D84; G02

${ }^{1}$ University of the Witwatersrand - School of Economic and Business Sciences, South Africa

\section{Introduction}

The aim of conventional finance theory is to provide an understanding of financial markets using models in which investors are viewed as rational. Rationality is seen as having two meanings; first, investors update their beliefs correctly when new information is collected, in alignment with the manner described by Bayes' Theorem (Laplace, 1812) and second, investors make choices that are normatively standard, i.e., they are

Correspondence concerning this article should be addressed to: Yudhvir Seetharam, University of the Witwatersrand - School of Economic and Business Sciences 1 Yale Road Braamfontein Johannesburg Gauteng 2001 South Africa T: +27117178117. Email:yudhvir.seetharam@wits.ac.za consistent with Savage's notion of Subjective Expected Utility (Savage, 1954). The simplicity of this concept makes it exceptionally attractive, but disappointment ensues when the data confirm that our basic notions of the share market are not explained by this framework (Barberis \& Thaler, 2003).

This particular study examines investor sentiment, proxied by consumer confidence, in South Africa and its effect on the Johannesburg Stock Exchange. Investor sentiment can be described as "a belief about cash flows that is not justified by the facts at hand" (Baker \& Wurgler, 2007, p. 129). Additionally, these investor beliefs are gauged relative to some norm or average (Brown \& Cliff, 2004), often the true fundamental value of the asset. Investigating these effects is vital: sentiment is seen as playing a critical role in the economy 
because it influences not only the business cycle but also the financial fluctuations within the economic system too (Sehgal, Sood, \& Rajput, 2009).

Investor sentiment is measured using the First National Bank and Bureau of Economic Research Consumer Confidence Index (hereafter known as CCI). Currently, the CCI is currently the only formal measure of consumer confidence publicly available in South Africa and is made available by the Bureau on a quarterly basis. It is measured via consumer surveys that provide regular evaluations of consumer attitudes and expectations, which are then used to evaluate economic trends and prospects. The survey is constructed using three questions, each carrying a different weight. The CCI is then computed as the average of the result of the three questions. The CCI is expressed as a net balance, thus revealing changes in consumer expectations. The net balance is derived as the difference between the percentage of respondents expecting an improvement and those expecting a decline (Kershoff, 2000).

The results of this study provide room for further debate on whether market performance can be foretold. Indeed, some studies find that consumer confidence is a lagging indicator of market performance in the United States. This implies that one cannot use this sentiment as a proxy in predicting market movements. However, Lemmon and Portniaguina (2006) and Zouaoui, Nouyrigat and Beer (2011) both provide evidence of how consumer confidence can be used to forecast macroeconomic activity and market crises, respectively. Individual investors may find this information important should they wish to speculate and exploit the perceived biases present in the share market in hopes of earning excess returns.

The remainder of this study is organized as follows: Section 2 presents a review of the literature on this topic, and Section 3 outlines the data and methodology used. Section 4 discusses the results, Section 5 considers the limitations of the studies and the opportunities for further research, and Section 6 concludes. Finally, Appendix A presents the distributional properties of the data used.

\section{Literature Review}

\section{Investor Sentiment}

There is a growing body of research pertaining to the effect of investor sentiment on the share market as a whole. The study of movements in share prices that are seemingly unjustified by fundamental pricing theories can be attributed to the term "animal spirits," which was made popular by Keynes (1937). An important factor that can be used to explain the crosssection of share returns but whose role was excluded in the development of classic finance theory is investor sentiment (Baker \& Wurgler, 2006). Standard finance theory dictates that share prices should reflect the present value of discounted cash flows (Schmeling, 2008); however, the fact that this is not always true highlights the possibility of additional factors, not all of which may be rational, in explaining share price movements.

A consumer confidence index reflects the combined expectations and the beliefs of investors concerning the fundamentals of markets and the economy $(\mathrm{Li}$, 2010). Lemmon and Portniaguina (2006), Qiu and Welch (2004) assert that a confidence index forms a direct measure of the general feelings of investors and that changes can measure the fluctuation of share returns especially for small firms. A common approach in the literature is to use a combined sentiment index consisting of several sentiment proxies. Utilizing such an index, Baker and Wurgler (2006) observe that investor sentiment has a significant effect on the cross section of stock returns.

The importance of studying investor sentiment is somewhat overshadowed by the difficulty in quantifying this concept, a difficulty that is further exacerbated by the fact that investor sentiment may be grouped into direct and indirect investor sentiment. Direct investor sentiment refers to investors' moods or expectations about the future and is usually measured via surveys and questionnaires. Indirect investor sentiment refers to a number of economic variables that are perceived to act as proxies for measuring investor sentiment (Uygur \& Taş, 2012). These can include mutual fund flows, trading volume, dividend premia, first-day returns and volumes on Initial Public Offerings, insider trading (Baker \& Wurgler, 2007) and closed-end fund discounts (Lee, Shleifer, \& Thaler, 1991). Moreover, Baker and Wurgler (2007) address this challenge by describing the "bottom up" approach of measuring investor sentiment, which makes use of biases in investor psychology to explain how investors react to past returns. They then endeavor to develop a contrasting model, namely the "top down" approach, which makes use of aggregate sentiment and its effects on market returns and on individual shares. 



\section{Data and Methodology}

\section{Sampling Data and Collection}

The CCI data are obtained from the Bureau for Economic Research, which is published quarterly. As outlined in Section 1, the CCI is expressed as a net balance and thus reveals changes in consumer expectations. The net balance is derived as the difference between the percentage of respondents expecting an improvement and those expecting a decline. The survey is constructed using three questions, each carrying a different weight, and the CCI is given as the weighted average of the results of the three questions. The three questions are as follows:

1. How do you expect the general economic position in South Africa to develop during the next 12 months? Will it improve considerably, improve slightly, deteriorate slightly, deteriorate considerably or don't know?

2. How do you expect the financial position in your household to develop in the next 12 months? Will it improve considerably, improve slightly, deteriorate slightly, deteriorate considerably or don't know?

3. What is your opinion of the suitability of the present time for the purchase of domestic appliances such as furniture, washing machines, refrigerators etc.? Do you think that for people in general it is the right time, neither a good nor a bad time or the wrong time?

The answers to questions 1 and 2 are weighted as follows: improve considerably $(+10)$, improve slightly $(+5)$, deteriorate slightly $(-5)$ and deteriorate considerably $(-10)$. The responses to question 3 are weighted as follows: right time to buy $(+10)$ and wrong time to buy (-10) (Kershoff, 2000).

JSE monthly price data are obtained from the Findata@Wits database, a financial database used for research maintained by the University of the Witwatersrand. Price data are collected for all companies listed on the JSE during the sample period in question, for a total of 867 companies. Those that delisted during the period were not removed to avoid any survivorship bias in the study.

\section{Description of Overall Research Design}

Given the two frequencies of data used, one must first transform one of the datasets to match the frequency of the other. One method by which to do so is to in- terpolate the CCI quarterly data in order to obtain monthly data. However, a potential limitation in using this method is that the interpolated values are not "real" in the sense of being available to an investor. In other words, while solving a statistical problem, the applicability of this method to a real world scenario is diminished. The second and more favorable alternative is to make use of the Time-Averaging method outlined by Armetso, Engemann and Owyang (2010). This method is viewed as superior because it converts the high frequency data (JSE share returns) to match the low frequency data (CCI data). For the purposes of this study, the time averaging method is employed.

Using these quarterly returns obtained from the time averaging methodology, an Artificial Market Index (AMI) is created on a price-weighted basis. As a comparable index to this AMI, data for the All Share Index (ALSI) is also obtained. These data are provided by the JSE on a monthly basis and are time averaged as described above.

JSE data are available from 1990 and CCI data from 1982 , and the sample period of the study will therefore run from 1992 to 2011 inclusive, a total of 20 years. This sample period is especially important in South Africa due to the numerous historical and world events that took place during that time. Furthermore, this period is sufficiently long to investigate any effects but short enough to ensure a minimal amount of noise enters the study. The JSE and CCI data for the sample period are divided into four quartiles for two reasons:

1. To assist in isolating the socio-economic effects, or the "noise" that enters the study.

2. Using smaller clusters of data provides a more indepth interpretation of whatever the results may be.

As a preliminary step, the distributional properties of the data are examined. This entails examining the independence and normality assumptions as well as stationarity. Stationarity is highly important in examining time series data because it determines if there is a long run relationship between share prices and investor sentiment. Should the data set be deemed nonstationary, differencing will be used as running tests on non-stationary variables results in spurious results.

To determine if there is a contemporaneous relationship between the CCI and the two indices, a correlation coefficient is calculated. A causal re- 
lationship between the CCI and the two indices is determined by conducting Granger causality tests at different lag orders. The test for a contemporaneous and causal relationship is completed for each subsample created. Granger causality involves running bivariate regressions of the following form:

$y_{t}=\alpha_{0}+\alpha_{1} y_{t-1}+\ldots+\alpha y_{t-1}+\beta_{1} x_{t-1}+\ldots+\beta_{t} x_{t-1}+\varepsilon_{t}$ $x_{t}=\alpha_{0}+\alpha_{1} x_{t-1}+\ldots+\alpha_{i} x_{t-1}+\beta_{1} y_{t-1}+\ldots+\beta y_{t-1}+u_{t}$

for all possible pairs of $(x, y)$ series in the group, where represents the appropriate lag length.

\section{Results and Discussion}

\section{Distributional Properties}

A correlogram of all three variables - CCI, AMI, and ALSI - is examined in testing for independence. The CCI data exhibit a degree of autocorrelation, indicating that the observations are not necessarily independent of each other. The opposite is observed for the AMI data: no traces of autocorrelation are uncovered, indicating that the observations are independent of each other. Finally, in considering the independence of the ALSI, it may be concluded that the ALSI observations are independent of each other. Details can be found in Appendix A.

Establishing stationarity is highly important for time series data and hence, the Augmented Dickey Fuller (ADF) test is conducted. The test results, shown in Table A4 in Appendix A, demonstrate that all three variables can be deemed stationary.

\section{Correlation Testing}

\section{CCI and ALSI}

During the period 1992 to 1996, the CCI and ALSI display moderate correlation with the correlation coefficient at the $5 \%$ level of significance. These results from Table 1 below indicate that during this period, there was a moderate concurrent relationship between these two variables.

Over the next five year period, 1997 to 2001, there is a very weak correlation between the CCI and the ALSI; nonetheless, this correlation coefficient is statistically insignificant. Thus, from Table 2 below, it may be concluded that there is no concurrent relationship between these two variables during this period.
The next five year period yields results similar to that observed in the previous five years. During the five years between 2002 and 2006, the CCI and ALSI are weakly negatively correlated, and this correlation coefficient is deemed statistically insignificant. Hence, the results from Table 3 below indicate that there is no concurrent relationship present between these variables during this period.

The final five-year block in the sample yields results similar to the majority of the sample. Between 2007 and 2011, the CCI and ALSI exhibit a weak and negative correlation that is statistically insignificant. Consequently, from Table 4 below, no concurrent relationship is found between the CCI and the ALSI during this five year period.

Overall, a moderate and significant concurrent relationship is found during only one time period, from 1992 to 1996 . The remaining periods show no evidence of a concurrent relationship, indicating that the evidence for a concurrent relationship is somewhat weak.

\section{CCI and AMI}

The correlation coefficient from Table 5 below indicates that between 1992 and 1996, the CCI and AMI demonstrate a moderate correlation. This correlation coefficient is statistically significant, indicating that there is a moderate concurrent relationship between these two variables. This result is similar to that obtained in the same period when considering the correlation between the CCI and ALSI.

Unfortunately, the subsequent five year period from 1997 to 2001 - provides evidence refuting the presence of a concurrent relationship. Although the CCI and the AMI are weakly negatively correlated during this time period, as seen in Table 6 below, the correlation coefficient is statistically insignificant and for that reason it may be concluded that there is no concurrent relationship between these two variables.

The five years between 2002 and 2006 provide evidence refuting the presence of a concurrent relationship. Table 7 below indicates that the CCI and AMI are negatively correlated, and although this relationship is stronger than those observed previously, it remains somewhat weak. Regardless, this correlation coefficient is statistically insignificant and it may thus be concluded that there is no concurrent relationship between these two variables. 
Table 1. CCI/ALSI Correlation 1992-1996

\begin{tabular}{ccc}
\hline & $1992-1996$ & $\mathrm{CCl}$ \\
\hline $\mathrm{ALSI}$ & $\mathrm{ALSI}$ & \\
& 1.00 & 1.00 \\
$\mathrm{CCl}$ & ---- & --- \\
\hline
\end{tabular}

Note: The $p$-values for the associated correlation coefficients are provided in the square brackets.

* - statistically significant at the $5 \%$ level of significance

Table 2. CCI/ALSI Correlation 1997-2001

\begin{tabular}{ccc}
\hline & $1997-2001$ & \\
\hline & ALSI & CCl \\
ALSI & 1.00 & \\
CCI & --- & 1.00 \\
\end{tabular}

Note: The p-values for the associated correlation coefficients are provided in the square brackets.

Table 3. CCI/ALSI Correlation 2002-2006

\begin{tabular}{ccc}
\hline & $\mathbf{2 0 0 2 - 2 0 0 6}$ & \\
\hline & ALSI & CCl \\
ALSI & 1.00 & \\
CCI & ---- & 1.00 \\
\end{tabular}

Note: The $p$-values for the associated correlation coefficients are provided in the square brackets.

Table 4. CCI/ALSI Correlation 2007-2011

\begin{tabular}{ccc}
\hline & $\mathbf{2 0 0 7 - 2 0 1 1}$ & \\
\hline & ALSI & CCl \\
ALSI & 1.00 & \\
& --- & 1.00 \\
CCl & -0.0379 & --- \\
\hline
\end{tabular}

Note: The p-values for the associated correlation coefficients are provided in the square brackets. 
Table 5. CCI/AMI Correlation 1992-1996

\section{2-1996}

\begin{tabular}{ccc}
\hline & AMI & $\mathrm{CCl}$ \\
ALSI & 1.00 & \\
$\mathrm{CCl}$ & --- & 1.00 \\
& 0.4713 & -- \\
\hline
\end{tabular}

Note: The $p$-values for the associated correlation coefficients are provided in the square brackets.

* - statistically significant at the $5 \%$ level of significance

Table 6. CCI/AMI Correlation 1997-2001

\section{$1997-2001$}

\begin{tabular}{ccc}
\hline & ALSI & $\mathrm{CCl}$ \\
ALSI & 1.00 & \\
$\mathrm{CCl}$ & --- & 1.00 \\
& -0.0116 & -- \\
\hline
\end{tabular}

Note: The p-values for the associated correlation coefficients are provided in the square brackets.

Table 7. CCI/AMI Correlation 2002-2006

\begin{tabular}{ccc}
\hline & $\mathbf{2 0 0 2 - 2 0 0 6}$ & $\mathrm{CCl}$ \\
\hline ALSI & AMl & \\
& 1.00 & 1.00 \\
CCl & --- & -- \\
\hline
\end{tabular}

Note: The p-values for the associated correlation coefficients are provided in the square brackets.

Table 8. CCI/AMI Correlation 2007-2011

\section{7-2011}

\begin{tabular}{ccc}
\hline & AMI & $\mathrm{CCl}$ \\
ALSI & 1.00 & \\
CCl & --- & 1.00 \\
& 0.0371 & - \\
\hline
\end{tabular}

Note: The p-values for the associated correlation coefficients are provided in the square brackets. 
The final five-year period from 2007 to 2001, shown in Table 8 below, provides similar results as those found above. The CCI and the AMI are found to have a positive but weak relationship that is statistically insignificant. Consequently, there is no evidence to support the presence of a concurrent relationship between these two variables during this time.

Overall, a moderate and significant concurrent relationship is found from 1992 to 1996 . The remaining period shows no evidence to support a concurrent relationship, an outcome that is consistent with the results of the previous tests.

The outcome of the analyses of the CCI and ALSI and CCI and AMI yield similar results. Evidence of a moderate concurrent relationship is found in the first five years, i.e., changes in the CCI have an impact on changes in the ALSI or changes in the AMI. The remainder of the sample period provides no evidence to support this relationship, and as a result, it may be concluded that the evidence for a concurrent relationship between these two sets of variables is somewhat weak.

\section{Granger Causality Tests}

\section{CCI and ALSI}

Table 9 shows the results of the Granger causality tests between the CCI and the ALSI at different lag orders for each sub-sample considered.

The results from output (1) show that for all lag orders, there appears to be no statistically significant Granger-causal relationship between the CCI and the ALSI in either direction. This means that from 1992 to 1996, changes in the CCI do not Granger-cause changes in the ALSI, and changes in the ALSI do not Granger-cause changes in the CCI. Output (2) yields similar results in that at all lag orders, there appears to be no statistically significant causal relationship between the CCI and the ALSI in either direction. This means that from 1997 to 2001, changes in the CCI do not Granger-cause changes in the ALSI, and changes in the ALSI do not Granger-cause changes in the CCI.

The results from output (3) indicate that during the period from 2002 to 2006 a statistically significant causal relationship is found at a lag of 9 months; however, while changes in the CCI Granger-cause changes in the ALSI at a 5\% level of significance, this relationship is not observed in the opposite direction. Additionally, at a lag of 12 months, a bidirectional Granger-caused relationship is found at the $10 \%$ level of significance - changes in the CCI Granger-cause changes in the ALSI and changes in the ALSI Granger-cause changes in the CCI. The remaining lag orders show no significant causal relationship between changes in the CCI and the ALSI.

Consistent with the previous time period, output (4), which considers the five years between 2007 and 2011 , indicates that a statistically significance unidirectional causal relationship is found at a lag of 9 months; changes in the CCI Granger-cause changes in the ALSI at a $5 \%$ level of significance. A similar relationship in the same direction is found at a lag of 12 months; however, this relationship is significant at the $10 \%$ level of significance. However, there are no statistically significant results uncovered in the opposite direction - changes in the ALSI do not Granger-cause changes in the CCI.

\section{CCI and AMI}

Table 10 below shows the results for the Granger causality tests between the CCI and the AMI at different lag orders for each sub-sample considered.

The results from output (1) reveal that at all lag orders between 1992 and 1996, there appear to be no statistically significant causal relationships between the CCI and the AMI in either direction. This means that during these five years, changes in the CCI do not Granger-cause changes in the AMI and changes in the AMI do not Granger-cause changes in the CCI. Output (2) yields results consistent with those observed in output (1). At all lag orders, there appears to be no statistically significant causal relationship between the CCI and the AMI in either direction. This means that during the period from 1997 to 2001, changes in the CCI do not Granger-cause changes in the AMI and changes in the AMI do not Grangercause changes in the CCI.

The results from the subsequent five year period - from 2002 to 2006 - given in output (3) show that at a lag of 9 and 12 months, changes in CCI Granger-cause changes in the AMI; these relationships are observed in one direction only and are statistically significant at the $5 \%$ level. The remaining lag orders show no statistically significant causal relationship between changes in the CCI and AMI. These results con- 
Table 9. CCI/ALSI Granger Causality Tests

\begin{tabular}{|c|c|c|c|c|c|c|}
\hline \multicolumn{7}{|c|}{ (1) $1992-1996$} \\
\hline & 3 months & 6 months & 9 months & 12 months & 15 months & 18 months \\
\hline $\mathrm{CCl}$ doe s not Grange r caus e ALSI & 0.67 & 0.53 & 0.57 & 0.85 & 0.49 & 0.87 \\
\hline ALSI doe s not Grange r caus e CCI & 0.53 & 0.83 & 0.71 & 0.89 & 0.88 & 0.72 \\
\hline \multicolumn{7}{|c|}{ (2) 1997-2001 } \\
\hline & 3 months & 6 months & 9 months & 12 months & 15 months & 18 months \\
\hline $\mathrm{CCl}$ doe s not Grange r caus e ALSI & 0.59 & 0.60 & 0.57 & 0.85 & 0.96 & 0.99 \\
\hline ALSI doe s not Grange r caus e CCl & 0.26 & 0.56 & 0.74 & 0.72 & 0.92 & 0.36 \\
\hline \multicolumn{7}{|c|}{ (3) $2002-2006$} \\
\hline & 3 months & 6 months & 9 months & 12 months & 15 months & 18 months \\
\hline CCI doe s not Grange r caus e ALSI & 0.15 & 0.31 & $0.017^{*}$ & $0.063^{* *}$ & 0.71 & 0.87 \\
\hline ALSI doe s not Grange r caus e CCI & 0.66 & 0.17 & 0.26 & $0.054^{* *}$ & 0.32 & 0.13 \\
\hline \multicolumn{7}{|c|}{ (4) $2007-2011$} \\
\hline & 3 months & 6 months & 9 months & 12 months & 15 months & 18 months \\
\hline $\mathrm{CCl}$ doe s not Grange r caus e ALSI & 0.14 & 0.40 & $0.036^{*}$ & $0.055^{* *}$ & 0.24 & 0.56 \\
\hline ALSI doe s not Grange r caus e CCl & 0.74 & 0.89 & 0.99 & 0.91 & 0.97 & 0.66 \\
\hline
\end{tabular}

Note: Statistical significance means that the null hypothesis in Column 1 can be rejected

* - statistically significant at the $5 \%$ level of significance

** - statistically significant at the $10 \%$ level of significance

cur with the results found for the identical time when changes in the CCI and ALSI were considered.

The final five-year block in the sample period from 2007 to 2011 - provides evidence for a causal relationship between the CCI and AMI. At a lag of 6,9 and 12 months there is a statistically significant unidirectional causal relationship between changes in the CCI and the AMI; in this case, changes in the CCI Granger-cause changes in the AMI. This result is similar to those found in the identical period when considering the causal relationship between changes in the CCI and ALSI. In accordance with the previous results, no statistically significant relationship is found in the opposite direction - changes in the AMI do not Granger-cause changes in the CCI.

\section{Discussion of Results}

It is evident from the above results that there are two distinct periods: between 1992 and 2001, no statistically significant Granger-caused relationships are identified when testing the CCI against both the ALSI and the AMI. Conversely, from 2002 to 2011, unidirectional, statistically significant Granger-caused relationships are found such that changes in the CCI do Granger-cause changes in the ALSI and AMI, usually at lag orders of three and four and in one case, the relationship was bidirectional. Possible reasons for this distinct separation include both global factors and those unique to the South African environment.

The period from 1992 to 1996 saw South Africa's first democratic election, the world's reacceptance of South Africa and South Africa's acceptance of the world as a trading partner. Nonetheless, the South African economy remained fragile and it is likely that consumers did not adjust their expectations correctly or in a timely manner; more than likely, consumers were uncertain as to whether the current conditions and economic and political reform would continue, and hence behaved in a possibly irrational manner (Simon, 1978). Therefore, the finding of no significant Granger-caused relationship between the two pairs of variables is disappointing, but not entirely surprising. 
Table 10. CCI/ALSI Granger Causality Tests

\begin{tabular}{|c|c|c|c|c|c|c|}
\hline \multicolumn{7}{|c|}{ (1) 1992-1996 } \\
\hline & 3 months & 6 months & 9 months & 12 months & 15 months & 18 months \\
\hline $\mathrm{CCl}$ doe s not Grange r caus e AMI & 0.25 & 0.33 & 0.19 & 0.42 & 0.55 & 0.80 \\
\hline AMI doe s not Grange r caus e CCl & 0.27 & 0.55 & 0.81 & 0.89 & 0.92 & 0.67 \\
\hline \multicolumn{7}{|c|}{ (2) 1997-2001 } \\
\hline & 3 months & 6 months & 9 months & 12 months & 15 months & 18 months \\
\hline $\mathrm{CCl}$ doe s not Grange r caus e AMl & 0.57 & 0.43 & 0.39 & 0.64 & 0.89 & 0.94 \\
\hline AMI doe s not Grange r caus e CCl & 0.40 & 0.73 & 0.89 & 0.85 & 0.93 & 0.15 \\
\hline \multicolumn{7}{|c|}{ (3) 2002-2006 } \\
\hline & 3 months & 6 months & 9 months & 12 months & 15 months & 18 months \\
\hline $\mathrm{CCl}$ doe s not Grange r caus e AMI & 0.11 & 0.17 & $0.011^{*}$ & $0.011^{*}$ & 0.19 & 0.56 \\
\hline AMI doe s not Grange r caus e CCl & 0.96 & 0.26 & 0.36 & 0.29 & 0.27 & 0.23 \\
\hline \multicolumn{7}{|c|}{ (4) $2007-2011$} \\
\hline & 3 months & 6 months & 9 months & 12 months & 15 months & 18 months \\
\hline $\mathrm{CCl}$ doe s not Grange r caus e AMI & 0.56 & $0.016^{*}$ & $0.005^{*}$ & $0.041^{*}$ & 0.18 & 0.79 \\
\hline AMl doe s not Grange r caus e CCl & 0.52 & 0.75 & 0.63 & 0.41 & 0.53 & 0.23 \\
\hline
\end{tabular}

Note: Statistical significance means that the null hypothesis in Column 1 is rejected

* - statistically significant at the $5 \%$ level of significance

** - statistically significant at the $10 \%$ level of significance

Conversely, the period from 1997 to 2001 was a much more prosperous time in South Africa, but not for the rest of the world. The year 1997 was peculiar as the world experienced both the formation of the Internet bubble and a stock market crash due to a global economic crisis scare. The bubble eventually burst in 2000, bringing many countries into a mild economic depression. At that time, South Africa was being built as a democratic and diverse nation and many changes were being implemented. Given the local and global conditions, it is quite surprising that there were no significant Granger-caused relationships identified between the two pairs of variables.

Following from the greater degree of integration between South Africa and the rest of the world, it is reasonable to expect that international financial trends, such as an investor sentiment effect, would become apparent in South Africa (as per Baker, Wurgler \& Yuan, 2012). This is exactly the result that was observed in the period from 2002 to 2011: it was found that changes in the CCI Granger-caused changes in both the ALSI and AMI with a lag of between 6 and 12 months. The lag of 6 months was observed in one scenario, with the most common finding being a lag of 9 and 12 months. There was only one instance of a bidirectional relationship, but overall there was weak evidence that changes in the ALSI or changes in the AMI Granger-caused changes in the CCI.

The evidence of the direction of this relationship contradicts the results found in the United States (Otoo, 1999), Canada (Karnizova \& Khan, 2010) and Europe (Jansen \& Nahuis, 2003). Evidence from these studies finds that share returns Granger-cause consumer confidence, but no causality is detected in the opposite direction. The contradiction in these results could be due to the frequency of the data used and, by implication, the lag order observed, or on a more macroeconomic level, the unique characteristics of the South African share market. Another possibility is the nature of the questions asked in the different consumer confidence indices used in different countries.

The five years between 2002 and 2006 were filled with many significant political, social and economic 

between consumer spending and stock market activity has been documented and the relationship explained using simple economics: when consumer spending increases, a part of this spending is directed toward the stock market. Huth, Eppright and Taube (1994) uncover evidence indicating that a number of consumer confidence indices are useful in predicting future values of aggregate consumer spending, as well and business and economic activity. This predictive property of investor sentiment provides evidence that it is indeed a leading indicator of the market, a relationship that is useful to many financial market participants.

\section{Limitations and Opportunities for Further Research}

This study is limited by the use of quarterly data, which led to a limitation in the number of observations used in the sample. Therefore, as with any empirical study, an improvement can be made by employing a larger data set, which can be achieved either by increasing the sample period or using a higher frequency data set. One must also bear in mind that increasing the sample period allows for a greater degree of noise to enter the study, and isolating any relationships or effects thus becomes a greater challenge.

Finally, although Granger causality is the most common method of testing for a causal relationship, other methods may yield robust results under different circumstances. The decision regarding which causality test to use should be made bearing in mind the type of data used, the frequency of the data and finally, the sample size.

The object of this paper was simply to determine if there is in fact a causal relationship between investor sentiment and JSE performance; however, many opportunities exist for further research with the goal of expanding on current knowledge. Considering that South Africa currently has one measure of investor sentiment available to the public - the Consumer Confidence Index - it would be beneficial to create a sentiment index using proxies for investor sentiment as the explanatory variables, as in Baker and Wurgler (2007), and then investigate the presence of a causal relationship between that index and share market performance. A further avenue to pursue would be to determine which types of shares are particularly susceptible to the effects of investor sen- timent; this would be particularly useful in South Africa due to the nature of the JSE. Finally, investigating the nature of the causal relationship - either direct or indirect - would make a valuable contribution to the topic of behavioral finance.

\section{Conclusion}

Conventional finance theory aims to provide an understanding of financial markets; under these theories, investors are assumed to be rational. However, as simple the concept of rationality may seem, this framework cannot explain basic ideas of financial markets. The shortcomings of standard finance theory allow for the development of new elements of research with the goal of providing a holistic understanding. One of these elements of research is the effect of investor sentiment on the share market. International research has established a causal relationship between investor sentiment and share market performance, with some analyses even delving deeper into the topic. Considering that there are no South African studies that investigate the link between these two variables, this paper investigates whether there is any relationship between investor sentiment - as measured by the Consumer Confidence Index - and JSE performance.

Statistical testing is conducted on three levels: determining first if there was a concurrent relationship, second, if there was a causal relationship, and finally, investigating the industry determinants of the CCI.

The evidence of a concurrent relationship is somewhat weak, and in each case a concurrent relationship is found in only one period, from 1992 to 1996. During this period, the concurrent relationship between changes in the CCI and changes in the ALSI or changes in the AMI are moderate. The remaining periods show no evidence to support a concurrent relationship, and it can therefore be concluded that there is very weak evidence of a concurrent relationship.

The results from the Granger causality tests create two distinct periods. The first two sub- samples 1992 to 1996 and 1997 to 2001 - show no evidence of a causal relationship between the CCI and the ALSI or the AMI. In the later sub-samples, however - 2002 to 2006 and 2007 to 2011 - the Granger causality tests show that changes in the CCI Granger-cause changes in the AMI, usually with a lag of 9 or 12 months. However, this relationship is purely unidirectional. The evi- 
dence also indicates that during this period, changes in the CCI Granger-cause changes the ALSI, also with a lag of 9 or 12 months. A bidirectional relationship is observed in one instance; however, the remaining relationships are unidirectional. Consequently, it can be concluded that a Granger causal relationship does exist. In answer to the question asked of this paper, we find that consumer confidence can be seen as a predictor of JSE performance with a lag of 9 or 12 months. Our results suggest that the CCI can be considered a leading indicator of the ALSI.

\section{Reference List}

Armetso, M. T., Engemann, K. M., \& Owyang, M. T. (2010). Forecasting With Mixed Frequencies. Federal Reserve Bank of St. Louis Review, 92 (6), 521-536.

Baker, M., \& Wurgler, J. (2006). Investor Sentiment and the Cross Section of Stock Returns. The Journal of Finance, 61 (4), 1645-1680.

Baker, M., \& Wurgler, J. (2007). Investor Sentiment in the Stock Market. Journal of Economic Perspectives, 21 (2), 129-151.

Baker, M., Wurgler, J., \& Yuan, Y. (2012). Global, lo$\mathrm{cal}$, and contagious investor sentiment. Journal of Financial Economics, 104 (2), 272-287.

Barberis, N., \& Thaler, R. (2003). A Survey of Behavioral Finance. Handbook of the Economics of Finance, 1 (1), 1053-1128.

Boone, L., Giorno, C., \& Richardson, P. (1998). Stock Market Fluctuations and Consumption Behaviour: Some Recent Evidence (Working Paper Series No. 208). OECD Economics Department.

Bremmer, D. (2008, March 16). Consumer Confidence and Stock Prices. Beliefs, Preferences and Stock Prices. Paper presented at the 72nd Annual Meeting of the Midwest Economics Association Hyatt Regency, Chicago, IL.

Brown, G. W., \& Cliff, M. T. (2004). Investor Sentiment and the Near-Term Stock Market. Journal of Empirical Evidence, 11 (1), 1-27.

Collins, D. (2001). The Relationship Between Business Confidence Surveys and Stock Market Performance. Investment Analysts Journal, 54, 9-17.

Da, Z., Engelberg, J., \& Gao, P. (2013). The Sum of All FEARS: Investor Sentiment and Asset Prices (Working Paper). Available at SSRN: http://ssrn. com/abstract $=1509162$
De Long, B., Shleifer, A., Summers, L. H., \& Waldmann, R. J. (1990). Noise Trader Risk in Financial Markets. The Journal of Political Economy, 98 (4), 703-738

Fisher, K. L., \& Statman, M. (2000). Investor Sentiment and Stock Returns. Financial Analysts Journal, 56 (2), 16-23.

Granger, C. W. (1969). Investigating causal relations by econometric models and cross-spectral methods. Econometrica: Journal of the Econometric Society, 37 (3), 424-438.

Hilton, D. J. (2001). The Psychology of Financial Decision Making: Applications to Trading, Dealing, and Investment Analysis. Journal of Psychology and Financial Markets, 2 (1), 37-53.

Huth, W. L., Eppright, D. R., \& Taube, P. M. (1994). The Indexes of Consumer Sentiment and Confidence: Leading or Misleading Guides to Future Buyer Behaviour. Journal of Business Research, 29 (3), 199-206.

Jansen, W. J., \& Nahuis, N. J. (2003). The Stock Market and Consumer Confidence: European Evidence. Economic Letters, 79 (1), 89-98.

Karnizova, L., \& Khan, H. (2010). The Stock Market and the Consumer Confidence Channel in Canada (Working Paper No. 1004E). University of Ottawa. Department of Economics.

Kershoff, G. (2000). Measuring Business and Consumer Confidence in South Africa (Working Paper). Bureau of Economic Research.

Keynes, J. M. (1937). The General Theory of Employment. The Quarterly Journal of Economics, 51 (2), 209-223.

Laplace, P. S. (1812). Théorie Analytique Des Probabilités [The Theory of Probability]. Paris: Ve. Courcier.

Lee, C. M., Shleifer, A., \& Thaler, R. H. (1991). Investor Sentiment and the Closed-End Fund Puzzle. The Journal of Finance, 46 (1), 75-109.

Lemmon, M., \& Portniaguina, E. (2006). Consumer Confidence and Asset Prices: Some Empirical Evidence. The Review of Financial Studies, 19 (4), 1499-1529.

Li, Y. (2010). Does Investor Sentiment affect CrossSectional Stock Returns on the Chinese A-Share Market? [Unpublished Master of Business dissertation]. Auckland University of Technology. 
Nickerson, R. S. (1998). Confirmation Bias: A Ubiquitous Phenomenon in Many Guises. Review of General Psychology, 2 (2), 175-220.

Otoo, M. W. (1999). Consumer Sentiment and The Stock Market. Board of Governors of the Federal Reserve System. Board of Governors of the Federal Reserve System. Retrieved from http://www.federalreserve.gov/PubS/feds/1999/199960/199960pap.pdf

Padayachee, V. (2011, September 10). Global economic recession: effects and implications for South Africa at a time of political challenges. Paper presented at the LSE conference: Responding to the Crisis in International Development, London. Retrieved from http://www.lse.ac.uk/internationaldevelopm ent/20thanniversaryconference/impactoftheglobalfc.pdf

Poterba, J. M., \& Samwick, A. A. (1995). Stock Ownership Patterns, Stock Market Fluctuations, and Consumption. Brookings Papers on Economic Activity, 26 (2), 295-372.

Qiu, L. X., \& Welch, I. (2004). Investor Sentiment Measures (Working Paper No. 10794). National Bureau of Economic Research.

Savage, L. J. (1954). The Foundations of Statistics. New York, NY: John Wiley \& Sons.

Schmeling, M. (2008). Investor Sentiment and Stock Returns: Some International Evidence (Working Paper No. 407). School of Economics and Management of the Hanover Leibniz University.

Sehgal, S., Sood, G. S., \& Rajput, N. (2009). Investor Sentiment In India: A Survey. The Journal of Business Perspective, 13 (2), 13-23.

Simon, H. A. (1985). Human nature in politics: The dialogue of psychology with political science. The American Political Science Review, 79 (2), 293-304.

Uygur, U., \& Taş, O. (2012). Modelling the Effects of Investor Sentiment and Conditional Volatility in International Stock Markets. Journal of Applied Finance and Banking, 2 (5), 239-260.

Vuchelen, J. (2004). Consumer Sentiment and Macroeconomic Forecasts. Journal of Economic Psychology, 25 (4), 493-506.

Zouaoui, M., Nouyrigat, G., \& Beer, F. (2011). How Does Investor Sentiment Affect Stock Market Crises? Evidence from Panel Data. Financial Review, 46 (4), 723-747. 


\section{Appendix A}

This appendix provides the tools used to examine the distributional properties of the CCI, AMI and the ALSI. Before proceeding with any statistical testing, it is necessary to test for the independence and stationarity of the three data sets being used.

Independence will be determined using correlograms for the three data series, provided in Figures A1, $\mathrm{A} 2$ and A3 below. Independence is tested by testing for autocorrelation - that is, correlations between the observations in one series. If there is no autocorrelation, the autocorrelations and partial autocorrelations at all lags should be close to zero and all the Q-statistics should be statistically insignificant at the appropriate confidence interval.

Stationarity will be determined by conducting the Augmented Dickey Fuller test. The Phillips-Perron and Kwiatkowski-Phillips-Schmidt-Shin tests can also be used; however, they test for essentially the same thing. Stationarity is highly important, especially when using time series data as it must be determined if the variables in question have a significant causal relationship or if it merely appears that way due to the variables trending over time.

Figure A1. Correlogram of CCI Data

\begin{tabular}{|c|c|c|c|c|c|c|}
\hline Autocorrelation & Partial Correlation & & $A C$ & PAC & Q-Stat & Prob \\
\hline ***|. | & ***|. | & 1 & -0.433 & -0.433 & 15.566 & 0.000 \\
\hline.$\left.\right|^{*}$ &. & 2 & 0.147 & -0.049 & 17.390 & 0.000 \\
\hline. &.$||$. & 3 & -0.030 & 0.019 & 17.465 & 0.001 \\
\hline.$*$ &..$^{*} .1$ & 4 & -0.088 & -0.107 & 18.127 & 0.001 \\
\hline.$\left.\right|^{*}$. &.$\left.\right|^{*}$ & 5 & 0.185 & 0.128 & 21.126 & 0.001 \\
\hline.$*$ &.$*$ & 6 & -0.202 & -0.080 & 24.749 & 0.000 \\
\hline.$*$ & $* *$. & 7 & -0.088 & -0.279 & 25.448 & 0.001 \\
\hline.$\left.\right|^{*}$. &. & 8 & 0.127 & -0.005 & 26.908 & 0.001 \\
\hline .1 & $\left.\right|^{*}$ & 9 & -0.015 & 0.116 & 26.930 & 0.001 \\
\hline.$*$ & $* *||$. & 10 & -0.144 & -0.234 & 28.885 & 0.001 \\
\hline.$\left.\right|^{* *}$ &.$\left.\right|^{*}$ & 11 & 0.215 & 0.132 & 33.283 & 0.000 \\
\hline$* * \mid$. &.$*$ & 12 & -0.268 & -0.101 & 40.214 & 0.000 \\
\hline.$\left.\right|^{* *}$ & .1 & 13 & 0.278 & 0.003 & 47.757 & 0.000 \\
\hline.$*$ & $.^{*} \mid$. & 14 & -0.191 & -0.079 & 51.395 & 0.000 \\
\hline .1. & .1 & 15 & 0.027 & 0.017 & 51.466 & 0.000 \\
\hline .1 &.$* 1$. & 16 & -0.019 & -0.189 & 51.505 & 0.000 \\
\hline .1. & .1 & 17 & -0.036 & -0.041 & 51.641 & 0.000 \\
\hline .1. & .1 & 18 & 0.030 & -0.024 & 51.733 & 0.000 \\
\hline .1 & .1 & 19 & -0.018 & -0.045 & 51.766 & 0.000 \\
\hline .1 & .1 & 20 & 0.009 & -0.027 & 51.774 & 0.000 \\
\hline. &. & 21 & -0.012 & 0.006 & 51.791 & 0.000 \\
\hline.$\left.\right|^{*}$. & .1 & 22 & 0.110 & 0.003 & 53.161 & 0.000 \\
\hline.$*$. & .1 & 23 & -0.127 & -0.041 & 55.011 & 0.000 \\
\hline.$\left.\right|^{*}$. & .1 & 24 & 0.159 & 0.035 & 57.988 & 0.000 \\
\hline.$*$. &.$*$. & 25 & -0.173 & -0.073 & 61.543 & 0.000 \\
\hline.$\left.\right|^{*}$. &.$* 1$. & 26 & 0.083 & -0.107 & 62.385 & 0.000 \\
\hline.$*$. &.$*$. & 27 & -0.099 & -0.109 & 63.605 & 0.000 \\
\hline. &.$* 1$. & 28 & -0.021 & -0.119 & 63.659 & 0.000 \\
\hline .1. &.$* 1$. & 29 & -0.012 & -0.135 & 63.677 & 0.000 \\
\hline .1. &.$* 1$. & 30 & -0.010 & -0.067 & 63.690 & 0.000 \\
\hline $.1^{*}$. &.$\left.\right|^{*}$. & 31 & 0.110 & 0.092 & 65.323 & 0.000 \\
\hline .1. & .1. & 32 & 0.003 & 0.062 & 65.324 & 0.000 \\
\hline .1. & .1. & 33 & 0.011 & -0.058 & 65.341 & 0.001 \\
\hline .1. & .1. & 34 & -0.020 & -0.016 & 65.399 & 0.001 \\
\hline .1 &.$*$ & 35 & 0.001 & -0.165 & 65.400 & 0.001 \\
\hline.$*$ & ${ }^{* *} \mid$. & 36 & -0.089 & -0.218 & 66.576 & 0.001 \\
\hline
\end{tabular}


Figure A2. Correlogram of AMI Data

\begin{tabular}{|c|c|c|c|c|c|c|}
\hline Autocorrelation & Partial Correlation & & AC & PAC & Q-Stat & Prob \\
\hline$.\left.\right|^{*} . \mid$ & $.\left.\right|^{*} . \mid$ & 1 & 0.149 & 0.149 & 1.8388 & 0.175 \\
\hline .*. & **. & 2 & -0.127 & -0.153 & 3.2008 & 0.202 \\
\hline .*. & .1 . & 3 & -0.086 & -0.043 & 3.8239 & 0.281 \\
\hline $.1^{*}$. & . ${ }^{*}$. & 4 & 0.119 & 0.126 & 5.0381 & 0.283 \\
\hline.$||$. & .1. & 5 & 0.026 & -0.034 & 5.0977 & 0.404 \\
\hline. & .1. & 6 & -0.035 & -0.009 & 5.2064 & 0.518 \\
\hline.$*$. & .1. & 7 & -0.080 & -0.057 & 5.7776 & 0.566 \\
\hline .1 &. & 8 & 0.000 & 0.001 & 5.7776 & 0.672 \\
\hline .1. &.$* 1$. & 9 & -0.044 & -0.067 & 5.9601 & 0.744 \\
\hline .1. & .1. & 10 & 0.012 & 0.029 & 5.9742 & 0.817 \\
\hline .1. & .1. & 11 & -0.034 & -0.040 & 6.0843 & 0.868 \\
\hline.$* 1$. &.$*$. & 12 & -0.135 & -0.139 & 7.8319 & 0.798 \\
\hline. $\mid$ &. & 13 & -0.025 & 0.029 & 7.8938 & 0.850 \\
\hline .1 &.$* 1$. & 14 & -0.056 & -0.113 & 8.2102 & 0.878 \\
\hline .1 & .1 & 15 & 0.046 & 0.064 & 8.4213 & 0.906 \\
\hline.$*$. & **|. & 16 & -0.182 & -0.219 & 11.810 & 0.757 \\
\hline.$* 1$. &. & 17 & -0.088 & -0.018 & 12.608 & 0.762 \\
\hline .1. & .1. & 18 & 0.030 & 0.009 & 12.702 & 0.809 \\
\hline.$\left.\right|^{*}$. & .1. & 19 & 0.117 & 0.038 & 14.183 & 0.773 \\
\hline.$* 1$. & .*1. & 20 & -0.144 & -0.158 & 16.463 & 0.688 \\
\hline .1. & .1. & 21 & -0.040 & 0.019 & 16.645 & 0.732 \\
\hline .1. & .1. & 22 & 0.018 & -0.007 & 16.680 & 0.781 \\
\hline $.1^{*}$. & .1. & 23 & 0.096 & -0.004 & 17.736 & 0.772 \\
\hline.$\left.\right|^{*}$. &.$\left.\right|^{*}$. & 24 & 0.095 & 0.122 & 18.783 & 0.763 \\
\hline. & **|. & 25 & -0.093 & -0.184 & 19.818 & 0.756 \\
\hline .1. & .1. & 26 & -0.045 & 0.032 & 20.062 & 0.789 \\
\hline.$*$. &.$*$. & 27 & -0.097 & -0.179 & 21.217 & 0.776 \\
\hline. & **|. & 28 & -0.141 & -0.215 & 23.729 & 0.696 \\
\hline .1 &.$||$. & 29 & -0.052 & -0.037 & 24.075 & 0.725 \\
\hline .1. &.$* 1$. & 30 & 0.010 & -0.096 & 24.089 & 0.768 \\
\hline. & .1 & 31 & -0.052 & -0.051 & 24.450 & 0.792 \\
\hline.$\left.\right|^{*}$. & . . $^{*}$. & 32 & 0.122 & 0.082 & 26.495 & 0.741 \\
\hline .1 & .*1. & 33 & -0.001 & -0.076 & 26.495 & 0.781 \\
\hline .1. & .*. & 34 & 0.015 & -0.066 & 26.529 & 0.816 \\
\hline.$* 1$. & .1. & 35 & -0.110 & -0.059 & 28.277 & 0.782 \\
\hline$.\left.\right|^{*} . \mid$ &. & 36 & 0.120 & 0.054 & 30.438 & 0.730 \\
\hline
\end{tabular}


Figure A3. Correlogram of ALSI Data

\begin{tabular}{|c|c|c|c|c|c|c|}
\hline Autocorrelation & Partial Correlation & & $A C$ & PAC & Q-Stat & Prob \\
\hline.$||$. &.$||$. & 1 & -0.021 & -0.021 & 0.0377 & 0.846 \\
\hline. &. & 2 & -0.035 & -0.035 & 0.1385 & 0.933 \\
\hline. &. & 3 & -0.018 & -0.020 & 0.1664 & 0.983 \\
\hline. $\mid$ &. & 4 & 0.044 & 0.042 & 0.3337 & 0.988 \\
\hline.$*$ &.$*$ & 5 & -0.204 & -0.204 & 3.9781 & 0.553 \\
\hline. &. & 6 & 0.052 & 0.050 & 4.2217 & 0.647 \\
\hline. $\mid$ &. & 7 & -0.029 & -0.043 & 4.2963 & 0.745 \\
\hline. $\mid$ &. & 8 & -0.027 & -0.036 & 4.3645 & 0.823 \\
\hline. $\mid$ &. & 9 & -0.041 & -0.027 & 4.5227 & 0.874 \\
\hline. &. & 10 & 0.011 & -0.041 & 4.5350 & 0.920 \\
\hline. $\mid$ &. $\mid$ & 11 & 0.023 & 0.045 & 4.5867 & 0.950 \\
\hline.$*$ &.$*$ & 12 & -0.090 & -0.114 & 5.3685 & 0.945 \\
\hline.$*$ &.$*$ & 13 & -0.123 & -0.136 & 6.8446 & 0.910 \\
\hline.$* 1$. &.$* 1$. & 14 & -0.093 & -0.123 & 7.6964 & 0.905 \\
\hline. &. & 15 & 0.057 & 0.030 & 8.0295 & 0.923 \\
\hline.$^{*}||$. & ${ }^{*}||$. & 16 & -0.094 & -0.103 & 8.9400 & 0.916 \\
\hline. &. & 17 & 0.066 & 0.021 & 9.3991 & 0.927 \\
\hline.$*$ &.$^{*}$. & 18 & -0.080 & -0.140 & 10.070 & 0.930 \\
\hline .1 & .1 & 19 & 0.013 & -0.041 & 10.089 & 0.951 \\
\hline .1 & .1 & 20 & 0.025 & 0.031 & 10.156 & 0.965 \\
\hline .1 &.$*$. & 21 & -0.017 & -0.119 & 10.187 & 0.976 \\
\hline. & .1 & 22 & -0.001 & 0.014 & 10.187 & 0.985 \\
\hline$\left.\right|^{*}$. &.$\left.\right|^{*}$. & 23 & 0.158 & 0.095 & 13.044 & 0.951 \\
\hline$\left.\right|^{*}$. & $.1^{* *}$ & 24 & 0.189 & 0.216 & 17.213 & 0.839 \\
\hline. $\mid$ &. $\mid$ & 25 & -0.025 & -0.022 & 17.284 & 0.871 \\
\hline .1 &. & 26 & 0.009 & -0.042 & 17.295 & 0.900 \\
\hline.$^{*}$. & $* * \mid$. & 27 & -0.163 & -0.212 & 20.581 & 0.806 \\
\hline.$^{*}$. &.$*$ & 28 & -0.116 & -0.133 & 22.279 & 0.768 \\
\hline.$^{*}$. &.$* 1$. & 29 & -0.093 & -0.074 & 23.393 & 0.758 \\
\hline$\left.\right|^{*}$. & .1 & 30 & 0.109 & 0.039 & 24.948 & 0.728 \\
\hline .1 & .1 & 31 & -0.049 & -0.027 & 25.267 & 0.756 \\
\hline.$\left.\right|^{*}$. & .1 & 32 & 0.100 & 0.048 & 26.639 & 0.735 \\
\hline.$* 1$. &.$^{*}$. & 33 & -0.103 & -0.115 & 28.109 & 0.709 \\
\hline. &.$*$ & 34 & 0.000 & -0.130 & 28.109 & 0.751 \\
\hline.$* 1$. &.$^{*}$. & 35 & -0.075 & -0.114 & 28.934 & 0.755 \\
\hline .1 & .1 & 36 & 0.020 & 0.005 & 28.995 & 0.790 \\
\hline
\end{tabular}

Table A1. Stationarity Tests on CCI, ALSI and AMI

\section{Stationarity Tests}

\begin{tabular}{ccc}
\hline & T-s tat & P-Value \\
Consumer Confidence Index & -13.8614 & 0.0001 \\
All Share Index & -8.8933 & 0.0000 \\
Artificial Market Index & -7.5011 & 0.0000 \\
\hline
\end{tabular}

Note: * denotes statistical significance at the $5 \%$ level of significance; the critical value used above was -3.4677. 
